\title{
Enhanced dynamic performance of grid feeding distributed generation under variable grid inductance
}

\author{
Salman Harasis ${ }^{1}$, Saher Albatran ${ }^{2}$, Eyad Almaita $^{1}$, Khaled Alzaareer $^{3}$, Qusay Salem ${ }^{4}$, \\ Mamdouh Alghaythi ${ }^{5}$, Mohammad Arifur Rahman ${ }^{6}$ \\ ${ }^{1}$ Department of Electrical Power and Mechatronics Engineering, Tafila Technical University, Tafila, Jordan \\ ${ }^{2}$ Department of Electrical and Computer Engineering, Jordan University of Science and Technology, Irbid, Jordan \\ ${ }^{3}$ Department of Electrical Engineering, Philadelphia University, Amman, Jordan \\ ${ }^{4}$ Department of Electrical Engineering, Princess Sumaya University for Technology, Amman, Jordan \\ ${ }^{5}$ Department of Electrical Engineering, Jouf University, Sakaka, Saudi Arabia \\ ${ }^{6}$ Department of Electrical and Computer Engineering, University of Akron, Akron, United States of America
}

\begin{tabular}{|c|c|}
\hline Article Info & ABSTRACT \\
\hline $\begin{array}{l}\text { Keywords: } \\
\text { Grid impedance } \\
\text { Integral control } \\
\text { PI control } \\
\text { Stability } \\
\text { State feedback control } \\
\text { Weak grid }\end{array}$ & $\begin{array}{l}\text { Controlling weak grid-connected systems is very challenging. In transient, } \\
\text { frequency and voltage oscillations may lead to voltage and/or frequency } \\
\text { stability problems and finally lead to system collapse. During steady-state } \\
\text { operation and at the point of common coupling (PCC), voltage degradation } \\
\text { and grid voltage background harmonics restrict the inverter's functionality, } \\
\text { reduce the power flow capability and cause poor power quality. With weak } \\
\text { grid connection, grid impedance variance will contaminate the voltage } \\
\text { waveform by harmonics and augment the resonance, destabilizing the } \\
\text { inverter operation. In this paper, complete mathematical modeling is carried } \\
\text { out and state feedback-plus-integral control is implemented to support the } \\
\text { stabilization of the system. The proposed controller is adopted to provide a } \\
\text { smooth transient under sudden load change by controlling the injected grid } \\
\text { current under different grid inductance values. Furthermore, the proposed } \\
\text { control is used to reduce the order and size of the inverter output filter while } \\
\text { maintaining system stability. The proposed control has been compared with } \\
\text { the conventional proportional integral (PI) controller under different } \\
\text { scenarios to validate its effectiveness and to strengthen its implementation as } \\
\text { a simple controller for distributed generator applications. }\end{array}$ \\
\hline
\end{tabular}

This is an open access article under the CC BY-SA license.

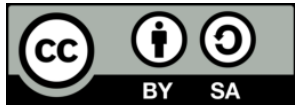

\section{Corresponding Author:}

Salman Harasis

Department of Electrical Power and Mechatronics Engineering, Tafila Technical University

Jordan-Tafilah 66110 P. O. Box 179

Email: salmanharasis@ttu.edu.jo

\section{INTRODUCTION}

The reliable performance of power electronic-based distributed generators (DGs) is a major research interest in different applications of grid-connected systems [1], [2]. This research interest grown to enable the expansion of reliable DGs in microgrids [3]. The high reliability of DGs and the ability to safely handle a considerable load variation without source tripping or shedding the connected loads are attained by preserving the voltage and the frequency within the allowable limits [4], [5]. The control structures of DGs are to be developed such that the grid requirements imposed by the utility are met in a viable and economical way under stiff and weak grid connections [6], [7].

Figure 1 shows the equivalent circuit of inverter grid-connected system. Inverter grid-connected control system is built based on the conventional output feedback control where some of the state variables are to be estimated to complete the control loop. Yet, state feedback control provides complete controllability 
to the system as the state variables can be directly accessed and utilized for the control process. This allows to place the poles at the desired location.

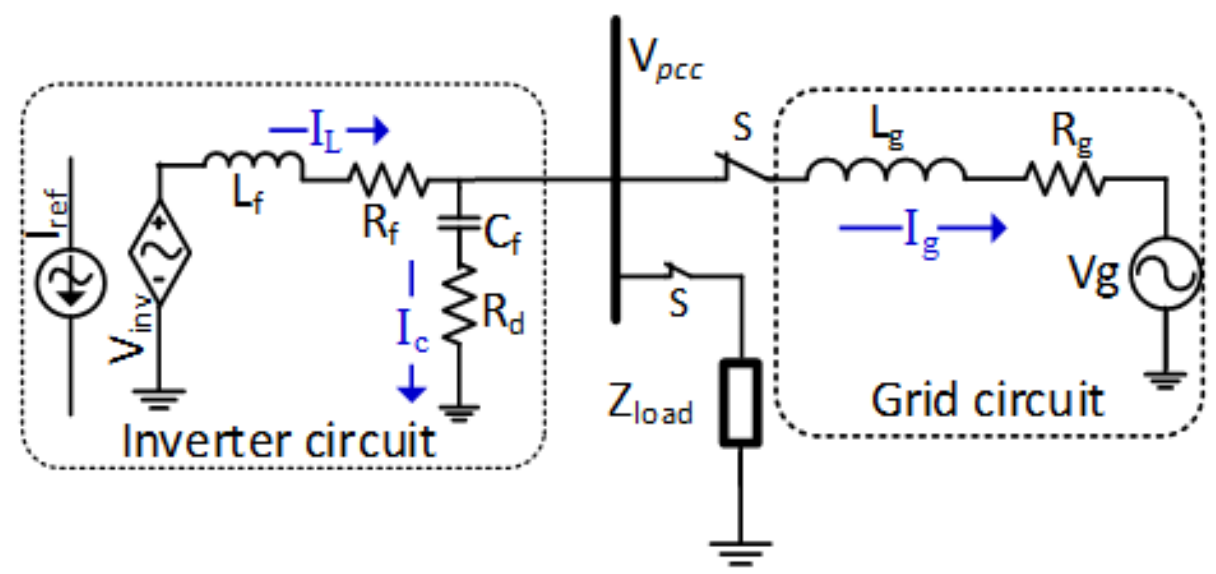

Figure 1. Simplified equivalent circuit of the inverter grid-connected system

State feedback control is implemented in different applications as it is broader and more inclusive than transfer function-based design [8], [9]. The pole location of the closed-loop system can be allocated independently based on the desired performance and reasonable control effort. As a direct and straight forward approach, pole placement can be implemented to design the controller gains based on system preferred specification.

State feedback has been maturely discussed and implemented in literature as a candidate control strategy for several applications. In study [10], current feedback control is designed for grid-connected voltage source inverters (VSIs) by splitting inductor-capacitor-inductor (LCL)-filter's capacitor into two parts proportionally. A state feedback current controller for inverter operation for photovoltaic and fuel cell power conditioning system is proposed in [11]. The control is designed to track a sine reference function algorithm and outer DC-link voltage proportional-integral (PI) controller using a notch filter.

Grid-forming and grid-feeding DGs are the two main types of DGs integrated into microgrids [12]. Both types have the same inverter circuit configuration, but the controller is different. In the grid-forming, DG is set to control voltage and frequency. This type is necessary for islanded microgrids to regulate the voltage and frequency in the absence of the main grid. In grid-feeding systems, the converter controls the voltage and frequency while DG stays synchronized with the grid and supplies the required power commanded by the controller. Grid-forming DGs are characterized as voltage sources with small equivalent impedance. In contrast, grid-feeding DGs are controlled as current sources with high equivalent impedance interfacing the utility grid. Consequently, grid-feeding DG has to be strongly connected to the grid phases to accurately regulate the Watt and Var injected into the grid [13]. The grid-supporting type is considered as a hybrid type between grid-forming and grid-feeding types that requires additional control loops to control the frequency and voltage through the active and reactive output powers. The characteristics of each type are presented in Table 1.

Table 1. Main features of typical DG types

\begin{tabular}{ccc}
\hline Grid Forming & Grid Feeding & Grid Supporting \\
\hline Acts as a voltage source. & Acts as a current source. & Acts as a voltage source. \\
Islanded operation. & Grid-connected. & Droop control/PQ control. \\
Constant frequency and voltage or & PQ (current control) & Necessary when switching from grid- \\
droop control. & Usually, MPPT controlled. & connected to islanded \\
Slow transient. & PLL-based. & \\
& Poor transient frequency dynamics. & \\
\hline
\end{tabular}

The current control strategy is used to control the amount of grid injected current based on d- and $\mathrm{q}$-axes current commands. It is also known as PQ control as the active power (P) is controlled through the $\mathrm{d}$-axis current command, and the reactive power $(\mathrm{Q})$ is controlled through the q-axis current command. The 
implementation of current control for LCL filtered grid-connected converters is proposed in [14]. The feedback gains were obtained to guarantee the active damping of the LCL filter complex poles. A control technique of current feedback for VSI interfaced a utility grid is proposed in [15] where the weighted average current feedback is used to minimize the distortion caused by the harmonics' and enhance system stability. Gaiceanu [16] implement state feedback control to stabilize the dc-link of grid-connected systems and reduce the ripple. Therefore, the system efficiency can be maintained high. Design of state space based PI control for grid-connected DG based on state feed feedback were discussed in [17]. An exact steady-state tracking based current control for utility interaction inverters with dual boost choppers is proposed in [18]. The developed controller is designed to ensure balanced voltage and accurate current tracking. Voltage feedforward decoupling strategy is proposed in [19]. The grid current's vulnerability due to utility grid voltage harmonics is reduced using the feedforward of grid voltage. A DC side control method of the grid-tie inverter is presented in [20]. The weak grid dynamics are smoothed by controlling the energy of the dc-link capacitor used to balance the ac side power. The enhancement of DG dynamic performance considering the output filter type and grid characteristics has not been clearly addressed in the literature. Moreover, stabilizing the system frequency under transient operating conditions and investigating the effect of the filter parameters on system stability has not been clearly discussed and investigated for the intended application. Even though the implementation of the PI-controller is straightforward, it has remarkable impact on system performance that is:

- In nested loop control systems, where multiple PI control loops are used, all PI controllers will not drive the error to zero concurrently. This might cause an integral error windup. Therefore, the non-zero error increases and causes controller issues that deteriorate the controller performance. As a result, the PI would not be sufficient, and an anti-windup control scheme should be used.

- As the proportional controller is responsible for shaping the transient response and the integral controller is accountable for driving the steady-state error to zero, tuning these gains is a time-consuming procedure [21], [22]. The transient performance is enhanced and adjusting the PI gains is relaxed by applying an adaptive PI controller that ensures smooth system dynamics as discussed in [23].

The contribution of the proposed work can be summarized as:

- A complete mathematical modeling of the system under study is carried out in continuous and discrete time domains to study the impact of parameters on system dynamic operation.

- A feedback-plus-integral control strategy is developed to strengthen the dynamic stability of the inverter operation with optimal design of passive damped inductor-capacitor (LC) filter.

- Mitigating the impact of grid weakness on the dynamic performance of the connected DG is achieved.

- Moreover, the performance of reduced order filter is examined to affirm the superiority of the proposed control strategy over the conventional PI control.

By adopting the proposed control, the applications of grid-feeding DG can be extended and expanded integration of grid-feeding DGs can be achieved. Moreover, as the proposed control strategy can stabilize the system and damps the dynamics effectively, the size and complexity of the output filter can be minimized. The organization paper is done as follows: the model of the weak grid is discussed in section 2 . In section 3, the control system under study is represented in state space model. In section 4, a control model is presented, the simulation results are discussed in section 5. Finally, the paper is summarized in section 6.

\section{VOLTAGE STIFFNESS AND STABILITY OF WEAK GRID-CONNECTED SYSTEM}

The power system points connected to DG, which are long distances from the power plant, are more likely to be weak where the voltage level fluctuates as that of a stiff grid [8]. This is clearly seen in rural electrification and remote areas. Grid low stiffness generally leads to increased voltage instability during dynamic operation of the system. Low system stiffness can also compromise the correct operation of protection systems and result in inverter systems disconnecting during disturbances. In microgrid operation, the weak system is characterized by high impedance and low inertia values, especially when most supply comes from renewable inverter-based micro-sources [9].

The grid stiffness indicates the capacity to transfer power with minimal variation in voltage. In other words, weak grid encounters larger challenges in transferring power. Thus, the maximum power that can be transacted with the utility grid becomes restricted. The existence of grid inductance reduces the filter resonance frequency and power transfer capability. As a result, this leads to voltage stability, harmonic, and resonance problems [3]. State feedback control provides the ability to shape the system's dynamics by placing the poles in the desired locations [24], [25]. Therefore, this control strategy can enhance stability and increases the damping of the system. This allows for a reduction of the LC filter resonance with grid inductance. The state feedback-plus-integral controller can achieve high control bandwidth and suitable stability margins by implementing pole placement design. Pole placement can straightforwardly identify the 
performance of closed-loop in terms of the optimum location of the system's poles and zeroes based on the desired dynamics. Thus, the pole placement control can minimize the effect of coupling impedance deviations on the controller. The state feedback gains can be determined to shape the impedance of the output filter at different frequency ranges to meet the impedance of the grid and stabilize the system under dynamic operating conditions.

\section{DEVELOPMENT OF STATE SPACE MODEL OF DISTRIBUTED GENERATION FEEDING A WEAK GRID}

The differential equations describing the system depicted in Figure 1 are developed according to Kirchhoff's laws as:

$$
\begin{aligned}
& L_{f} \frac{d i_{L}}{d t}+R_{f} i_{L}=V_{i n v}-V_{c}-R_{d}\left(i_{L}-i_{g}\right) \\
& C_{f} \frac{d V_{c}}{d t}=i_{L}-i_{g}
\end{aligned}
$$

The continuous-time state-space model is developed such that the inverter voltage and grid current are the inputs of the system, and the inverter output current is the output of the system as given in (3) and (4). The continuous-time plant model is developed by taking the Laplace transform of (1) and (2). The transfer function between filter's inductor current (the system output) and the difference between output voltage of the inverter and the capacitance-voltage can be derived based on (5) through (9).

$$
\begin{aligned}
& {\left[\begin{array}{c}
\dot{L}_{L} \\
\dot{V}_{c}
\end{array}\right]=\left[\begin{array}{cc}
\frac{-\left(R_{f}+R_{d}\right)}{L_{f}} & \frac{-1}{L_{f}} \\
\frac{1}{C_{f}} & 0
\end{array}\right]\left[\begin{array}{l}
i_{L} \\
V_{c}
\end{array}\right]+\left[\begin{array}{cc}
\frac{1}{L_{d}} & \frac{R_{f}}{L_{f}} \\
0 & \frac{1}{C_{f}}
\end{array}\right]\left[\begin{array}{c}
V_{i n v} \\
i_{g}
\end{array}\right]} \\
& i_{L}=\left[\begin{array}{ll}
1 & 0
\end{array}\right]\left[\begin{array}{l}
i_{L} \\
V_{c}
\end{array}\right] \\
& I_{g}=\left[V_{p c c}-V_{g}\right] \frac{1}{s L_{g}} \\
& I_{i n v}=\left[V_{i n v}-V_{p c c}\right] \frac{1}{R_{f}+s L_{f}} \\
& V_{p c c}=V_{c_{f}}+V_{R_{d}} \\
& V_{p c c}=\left[I_{i n v}-I_{g}\right] \frac{\left(1+R_{d} C_{f}\right)}{s C_{f}} \\
& G(s)=\frac{I_{L}(s)}{V_{i n v}(s)-V_{p c c}(s)}=\frac{1}{s L_{f}+R_{f}}
\end{aligned}
$$

The discrete-time state-space model is obtained from the continuous-time model using the bilinear transformation. The zero and pole mapping of the discrete transfer function is then generated to study the impact of parameter change on system stability. The equations used to generate the discrete state space are:

$$
A_{d}=e^{A T}=L^{-1}\left([s I-1]^{-1}\right), G_{d}=\int_{0}^{T} e^{A T} B_{1} d \tau, J_{d}=\int_{0}^{T} e^{A t} B_{2} d \tau, \mathrm{H}_{d}=C
$$

where $B_{1}=\left[\begin{array}{c}1 / L_{f} \\ 0\end{array}\right]$ and $B_{2}=\left[\begin{array}{l}R_{d} / L_{f} \\ -1 / C_{f}\end{array}\right]$.

The corresponding discrete matrices of the continuous-time model are: 


$$
\begin{aligned}
& A_{d}=\left[\begin{array}{cc}
\cos \left(\frac{T}{\sqrt{C_{f} L_{f}}}\right) & -\frac{\sqrt{C_{f}} \sin \left(\frac{T}{\sqrt{C_{f} L_{f}}}\right)}{L_{f}} \\
\frac{\sqrt{L_{f}} \sin \left(\frac{T}{\sqrt{C_{f} L_{f}}}\right)}{C_{f}} & \cos \left(\frac{T}{\sqrt{C_{f} L_{f}}}\right)
\end{array}\right], G_{d}=\left[\begin{array}{c}
\frac{\sqrt{C_{f}} \sin \left(\frac{T}{\sqrt{C_{f} L_{f}}}\right)}{L_{f}} \\
1-\cos \left(\frac{T}{\sqrt{C_{f} L_{f}}}\right)
\end{array}\right] \\
& J_{d}=\left[\begin{array}{c}
1-\cos \left(\frac{T}{\sqrt{C_{f} L_{f}}}\right) \\
-\frac{\sqrt{L_{f}} \sin \left(\frac{T}{\sqrt{C_{f} L_{f}}}\right)}{C_{f}}
\end{array}\right]
\end{aligned}
$$

\section{CONTROL ALGORITHM AND SYSTEM MODELING}

It is important to mention that the effectiveness of state feedback control depends on how accurate and realistic the modeling is. For accurate state feedback control design, all system's physical parameters should be taken into account. Therefore, the equivalent series resistor (ESR) of the filter elements and the damping resistor are considered in the modeling.

Figure 2 shows the block diagram of the physical parameters derived from the circuit of Figure 1. The current control technique using PI control is added to the block diagram of Figure 2 and given in Figure 3. The mathematical model of the system is created and pole-placement using Ackerman method [26] is used to place the closed-loop poles in the desired location. The current control loop has its open-loop poles near the unit circle on the z-plane, making the system prone to noise and resonance as shown in Figure 4.

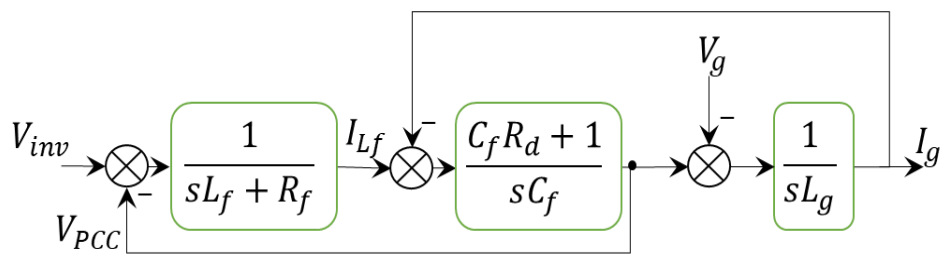

Figure 2. Diagram of grid connected DG

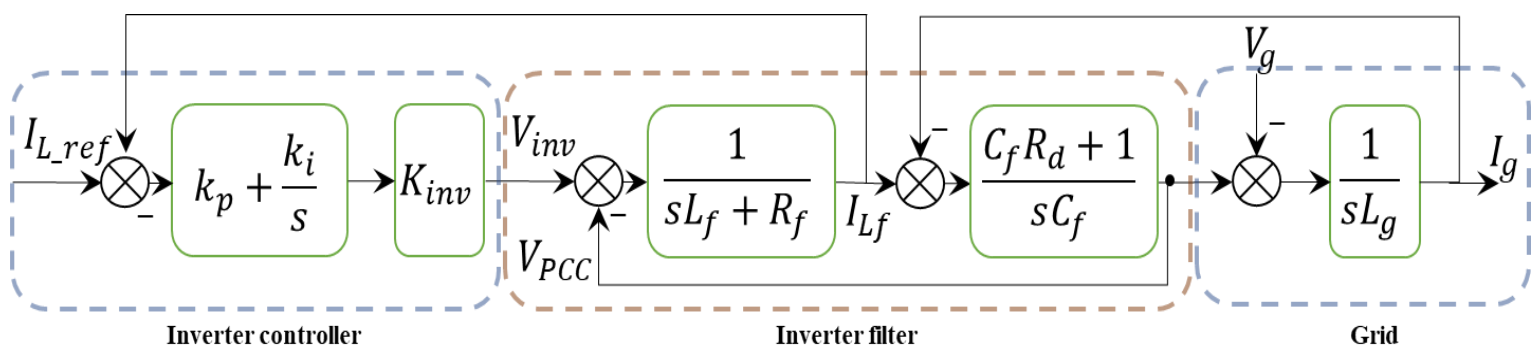

Figure 3. The block diagram of the whole system applying current control

The mapping shown in Figure 4(a) reveal that adding passive damping is necessary to stabilize the system due to the original poles' existence on the unit circle. This value is found to be adequate when the closed-loop system is applied (PI control). Figure 4(b) shows a zoomed version of Figure 4(a) of the poles near the unity circle. Figure 5 shows the effect of changing the output filter inductance and the shunt capacitor on the open-loop system.

Implementing the state feedback control is done by taking the measured values of the output filter current $\left(\mathrm{I}_{\mathrm{L}}\right)$ and the PCC voltage $\left(\mathrm{V}_{\mathrm{PCC}}\right)$ as state variables instead of the capacitor voltage. These quantities are again injected in the input of the same current loop. The state feedback control enhances the transient response of the system and damps the resonance. The integral controller is applied to ensure zero steady-state error by canceling the zero at $\mathrm{z}=1$ as shown in Figure 4. This process is depicted in Figure 6 . 


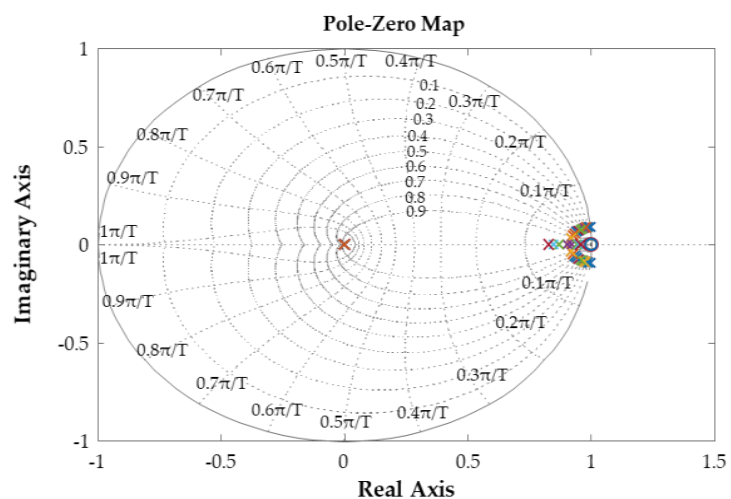

(a)

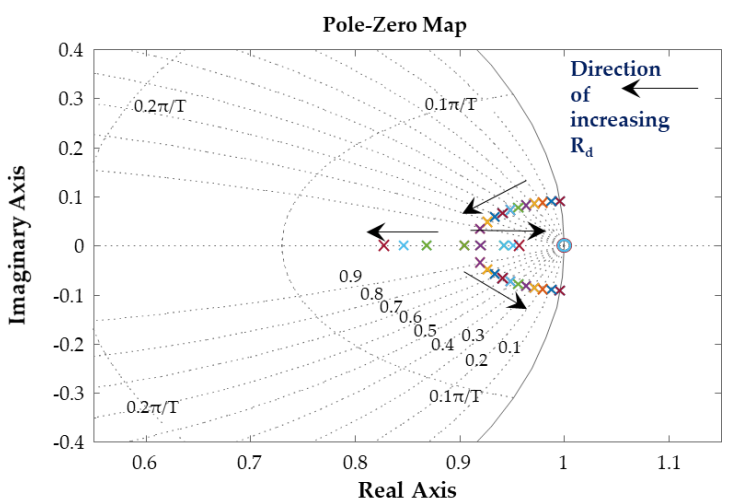

(b)

Figure 4. Discrete time domain analysis of the system illustrated by (a) zero pole mapping of the open-loop system showing the effect of increasing the damping resistor $\left(R_{d}\right)$ from (0-14 $\Omega$ ) of the open-loop system, and (b) a zoomed version from 'a'

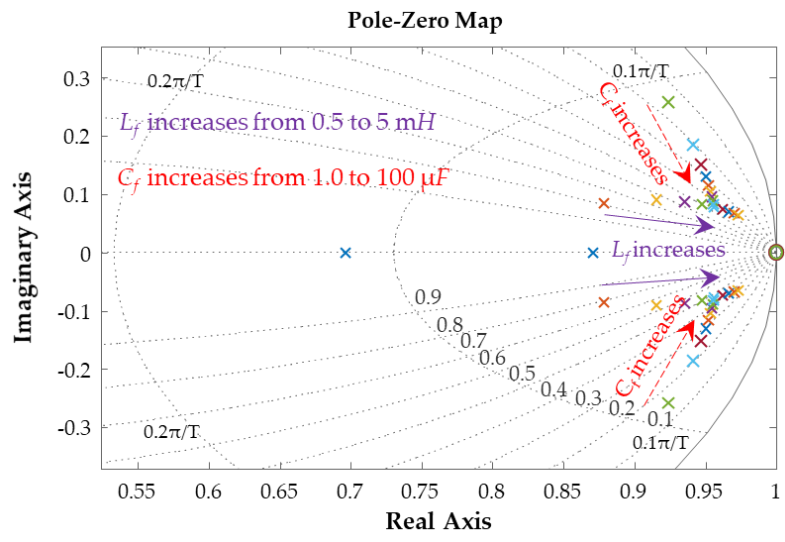

Figure 5. The effect of changing filter's capacitor and inductor values

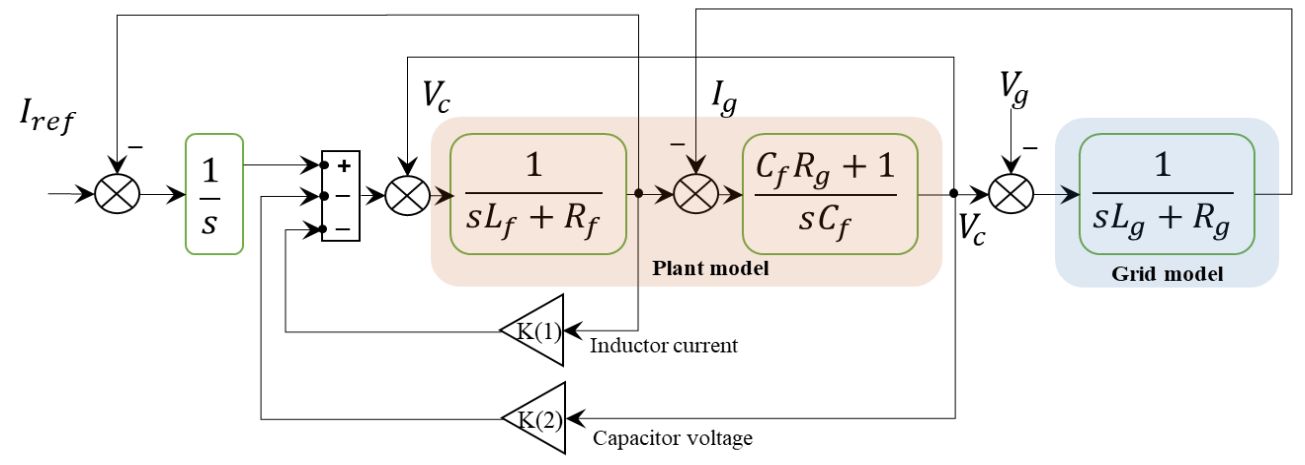

Figure 6. The implementation of state feedback control

\section{CASE STUDY RESULTS}

According to the system shown in Figure 1, the system has been built in MATLAB ${ }^{\circledR} /$ Simulink. The parameters of the system are given in Table 2. A step-change in the current command has been inserted at $\mathrm{t}=0.6 \mathrm{sec}$ to test the system robustness against disturbances where current command of the $\mathrm{d}$-axis is suddenly altered from 50 to $100 \mathrm{~A}$. The system has been tested under stiff (case 1) and weak (case 2) grid conditions, implementing both controllers. 


\begin{tabular}{cc} 
Table 2. System parameters \\
\hline Parameter & Value \\
\hline$L_{f}$ & $3 \mathrm{mH}$ \\
$C_{f}$ & $100 \mu \mathrm{F}$ \\
$R_{d} / R_{f}$ & $5 \Omega / 0.2 \Omega$ \\
$L_{g}$ & $0.1 L_{f}<L_{g}<1.4 L_{f}$
\end{tabular}

\subsection{Case-1: stiff grid connection $\left(\mathrm{L}_{\mathrm{g}}=\mathbf{0 . 2} \mathrm{L}_{\mathrm{f}}\right)$}

The comparative results are given in Figure 7. The waveform of the grid injected current is given in Figure 7(a). The PCC voltage is given in Figure 7(b), where the actual d- and q- axes currents are shown in Figure 7(c). The system frequency is shown in Figure 7(d). It is understandable from the figures that the state feedback can move the poles from the original open-loop undesired location into the desired location based on the specified overshot and damping ratio values. To simplify the implementation, $\mathrm{V}_{\mathrm{C}}$ is replaced by the PCC voltage.

\subsection{Case-2: weak grid connection $\left(\mathrm{L}_{\mathrm{g}}=1.4 \mathrm{~L}_{f}\right)$}

The results of the case when the grid inductance is increased to $1.4 \mathrm{~L}_{f}$ are obtained to represent a weak grid connection. Figure 8(a) compares the grid injected current under both controllers. Figure 8(b) compares the PCC voltage profile. The d-axis current is compared in Figure 8(c). The q-axis current is shown in Figure 8(d). The system frequency profile is shown in Figure 8(e) where the proposed control is able to stabilize the frequency under a step load change compared to the conventional PI control. It can be observed that the dynamics are effectively damped using the state feedback control compared to the conventional PI controller. The system loses stability after the current command has been changed. Under low grid impedance, the steady-state performance of traditional PI and state feedback+integral controllers satisfy IEEE-519 standard. The output waveforms are sinusoidal, and the voltage total harmonic distortion $\left(\right.$ THD $\left._{\mathrm{V}}\right)$ is less than 5\%. Increasing the grid inductance results in increased harmonics and the level of voltage degradation. An FFT based comparison for both cases are provided in Table 3 to calculate the voltage THD.

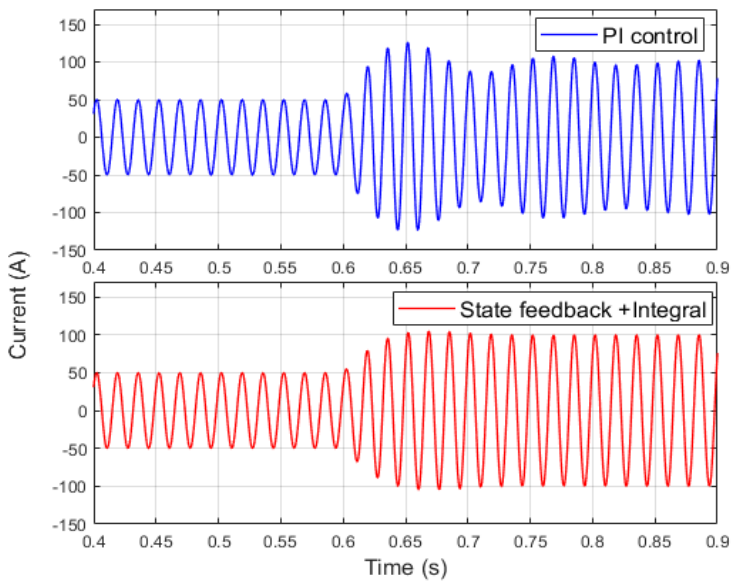

(a)

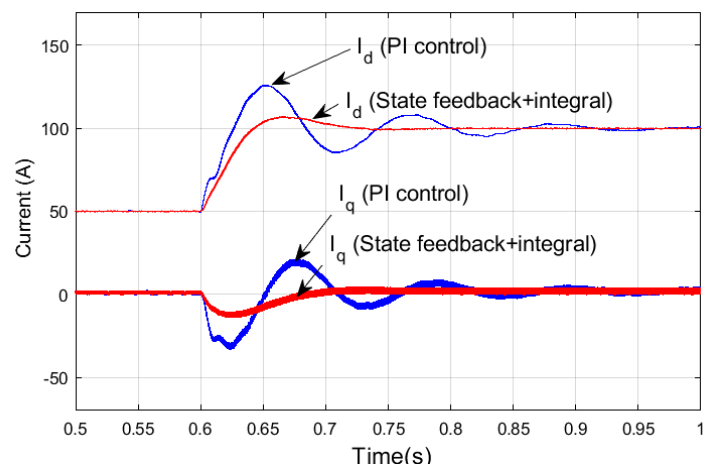

(c)

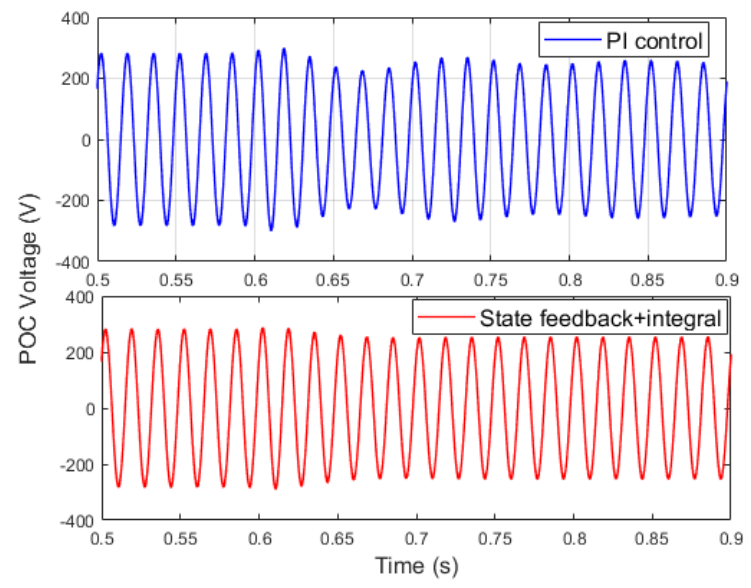

(b)

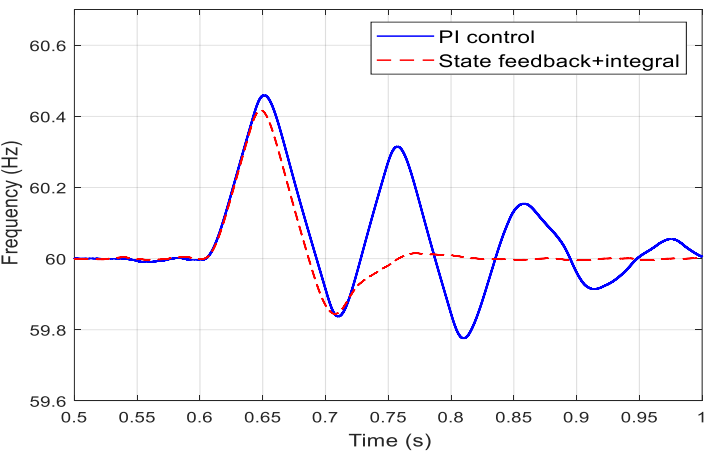

(d)

Figure 7. Output waveforms when current command changes from 50 to $100 \mathrm{~A}$ at $\mathrm{t}=0.6 \mathrm{~s}$ (Case 1): (a) grid injected current, (b) PCC voltage, (c) the actual d- and q-axis currents, and (d) the PCC frequency 


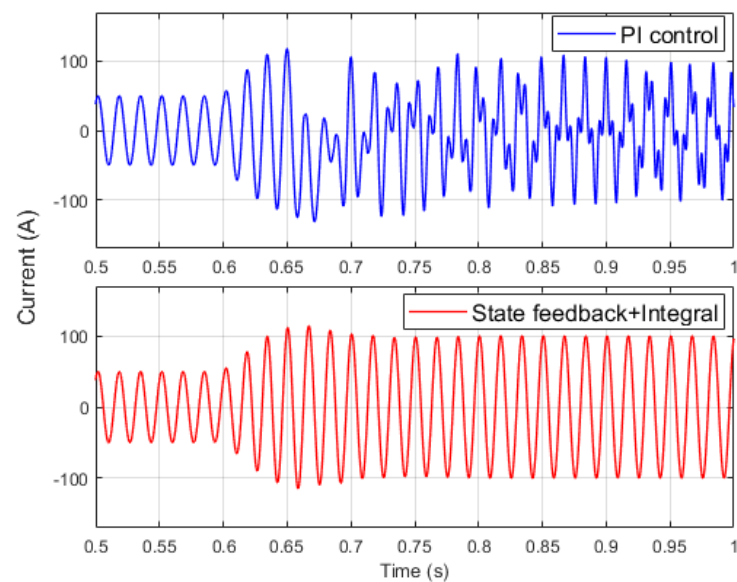

(a)

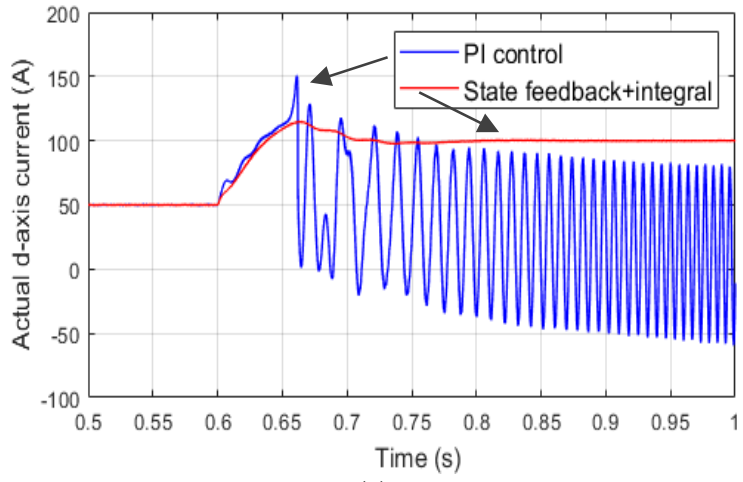

(c)

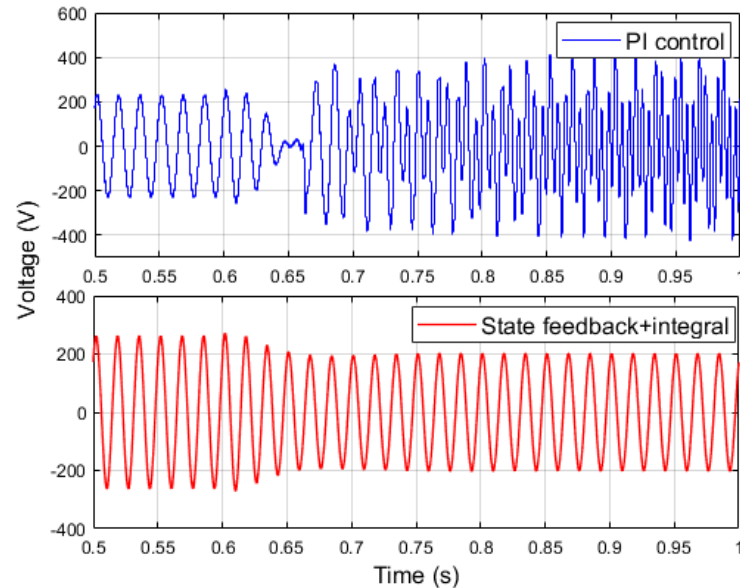

(b)

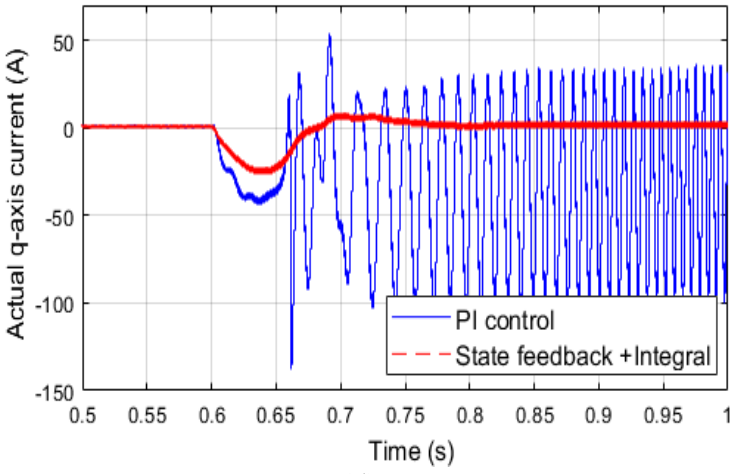

(d)

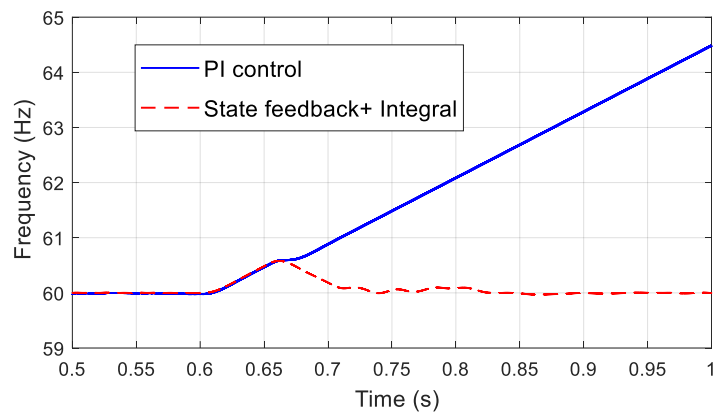

(e)

Figure 8. Output waveforms when current command changes from 50-100 A at $\mathrm{t}=0.6 \mathrm{~s}$ ) (Case 2): (a) grid injected current, (b) PCC voltage, (c) actual $d$-axis current, (d) actual $q$-axis current, and (e) system frequency

Table 3. Voltage THD results at different grid inductance values

\begin{tabular}{ccc}
\hline Grid Inductance & THD $_{\mathrm{V}}$ (state feedback) & $\mathrm{THD}_{\mathrm{V}}(\mathrm{PI})$ \\
\hline$L_{g}=0.8 L_{f}$ & $2.66 \%$ & $3.38 \%$ \\
$\mathrm{~L}_{\mathrm{g}}=1.2 L_{f}$ & $4.12 \%$ & $11.23 \%$ \\
$\mathrm{~L}_{\mathrm{g}}=1.4 L_{f}$ & $16.21 \%$ & Unstable \\
\hline
\end{tabular}

To further show the superiority of the proposed control, Figure 9(a) and Figure 9(b) are provided to compare the voltage and grid injected current profiles under PI and proposed controller, respectively. In this case, a $1^{\text {st }}$ order filter is used instead of a $2^{\text {nd }}$ order filter. Here, the RC branch is removed in the output filter. A step current change has been introduced similar to the previous cases (from 50 to $100 \mathrm{~A}$ ). The results show that the voltage THD (THDv) at PCC is $14.51 \%$ when the PI controller is adopted, and it is $8.81 \%$ when the state feedback method is used. It is clear from the current waveforms that the proposed control can stabilize the current and improves the tracking capability of the reference current. The current waveform exhibits an 
overshoot of $25 \%$. These are promising results that help reduce the filter's size and cost when state feedback control is implemented.

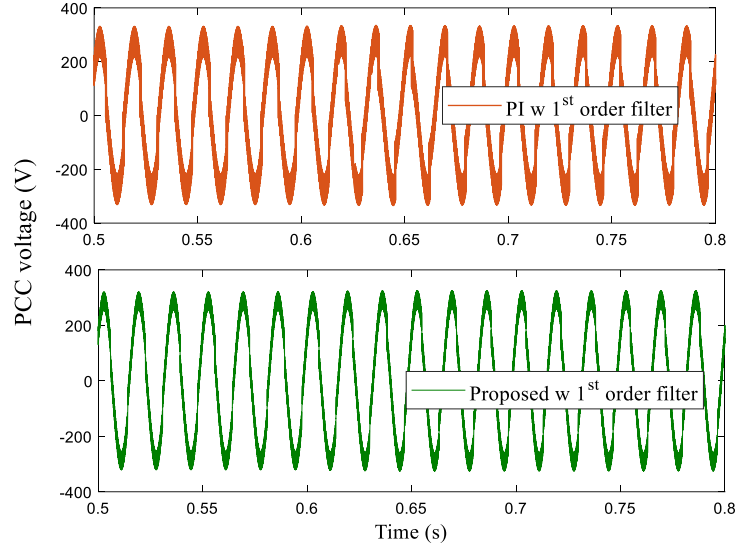

(a)

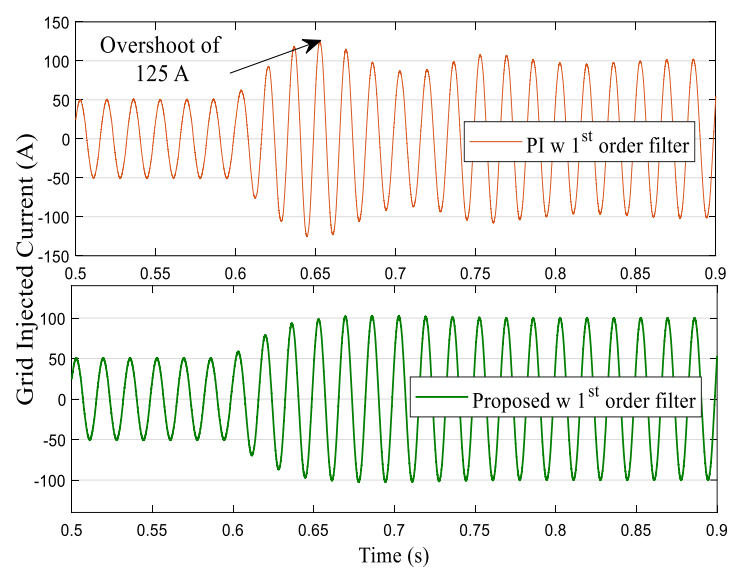

(b)

Figure 9. Comparative results between the proposed control and the PI control: (a) the PCC voltage and (b) the grid injected current waveforms implementing PI control and state feedback_plus_integral control with $1^{\text {st }}$ order L-type filter under stiff grid connection $\left(\mathrm{L}_{\mathrm{g}}=0.2 \mathrm{~L}_{f}\right)$

\section{CONCLUSION}

Weak grid connection reduces the stability and augments the harmonic resonance in grid-connected systems. Applying state feedback-plus-integral controller can effectively increase the stability margins and damp the resonance. Implementing the state feedback-plus-integral is straightforward using pole placement technique if the physical circuit modeling is available. The obtained results show the superiority of state feedback control system in stabilized the system under different grid conditions. The proposed work can stabilize the system under a sudden change in the current command. From a hardware point of view, the proposed controller can reduce the order of the needed filter by implementing state feedback control. As a result, the proposed control strategy provides a cost- efficient solution for DG applications. Moreover, the improved performance of DG under different grid characteristics would give the confidence to deploy more renewable based DGs into power network.

\section{REFERENCES}

[1] S. Lakshminarayanan, B. M. Kiran Kumar, S. Nagaraja Rao, and S. Pranupa, "Current mode control of single phase grid tie inverter with antiislanding," International Journal of Power Electronics and Drive Systems (IJPEDS), vol. 12, no. 1, pp. 241-248, Mar. 2021, doi: 10.11591/ijpeds.v12.i1.pp241-248.

[2] S. Albatran, S. Harasis, M. Ialomoush, Y. Alsmadi, and M. Awawdeh, "Realistic optimal power flow of a wind-connected power system with enhanced wind speed model," IEEE Access, vol. 8, pp. 176973-176985, 2020, doi: 10.1109/ACCESS.2020.3027065.

[3] E. Hendawi, "A high performance grid connected PV system based on HERIC transformerless inverter," Indonesian Journal of Electrical Engineering and Computer Science (IJEECS), vol. 20, no. 2, pp. 602-612, Nov. 2020, doi: 10.11591/ijeecs.v20.i2.pp602-612.

[4] A. Rostami, M. Bagheri, S. B. Naderi, M. Negnevitsky, A. Jalilian, and F. Blaabjerg, "A novel islanding detection scheme for synchronous distributed generation using rate of change of exciter voltage over reactive power at DG-Side," in 2017 Australasian Universities Power Engineering Conference, AUPEC 2017, Nov. 2018, vol. 2017-Nov., pp. 1-5, doi: 10.1109/AUPEC.2017.8282417.

[5] M. H. Khan, S. A. Zulkifli, E. Pathan, E. Garba, R. Jackson, and H. Arshad, "Decentralize power sharing control strategy in islanded microgrids," Indonesian Journal of Electrical Engineering and Computer Science (IJEECS), vol. 20, no. 2, pp. 752-760, Nov. 2020, doi: 10.11591/ijeecs.v20.i2.pp752-760.

[6] A. Abdalrahman, A. Zekry, and A. Alshazly, "Simulation and Implementation of Grid-connected Inverters," International Journal of Computer Applications, vol. 60, no. 4, pp. 41-49, Dec. 2012, doi: 10.5120/9683-4117.

[7] J. Xu, S. Xie, and T. Tang, "Evaluations of current control in weak grid case for grid-connected LCL-filtered inverter," IET Power Electronics, vol. 6, no. 2, pp. 227-234, Feb. 2013, doi: 10.1049/iet-pel.2012.0192.

[8] H. Du, X. Hu, and C. Ma, "Dominant pole placement with modified PID controllers," International Journal of Control, Automation and Systems, vol. 17, no. 11, pp. 2833-2838, Jul. 2019, doi: 10.1007/s12555-018-0642-4.

[9] M. Mahmoudi, H. Lafari, and R. Jafari, "Frequency control of micro-grid using state feedback with integral control," in 20th Electrical Power Distribution Conference, EPDC 2015, Apr. 2015, pp. 1-6, doi: 10.1109/EPDC.2015.7330464.

[10] G. Shen, D. Xu, L. Cao, and X. Zhu, "An improved control strategy for grid-connected voltage source inverters with an LCL filter," IEEE Transactions on Power Electronics, vol. 23, no. 4, pp. 1899-1906, Jul. 2008, doi: 10.1109/TPEL.2008.924602. 
[11] H. S. Bae, S. J. Lee, K. S. Choi, B. H. Cho, and S. S. Jang, "Current control design for a grid connected photovoltaic/Fuel cell DC-AC inverter," in Conference Proceedings - IEEE Applied Power Electronics Conference and Exposition - APEC, Feb. 2009, pp. 1945-1950, doi: 10.1109/APEC.2009.4802939.

[12] C. K. Sao and P. W. Lehn, "Control and power management of converter fed microgrids," IEEE Transactions on Power Systems, vol. 23, no. 3, pp. 1088-1098, Aug. 2008, doi: 10.1109/TPWRS.2008.922232.

[13] J. Rocabert, A. Luna, F. Blaabjerg, and P. Rodríguez, "Control of power converters in AC microgrids," IEEE Transactions on Power Electronics, vol. 27, no. 11, pp. 4734-4749, Nov. 2012, doi: 10.1109/TPEL.2012.2199334.

[14] I. J. Gabe, V. F. Montagner, and H. Pinheiro, "Design and implementation of a robust current controller for VSI connected to the grid through an LCL filter," IEEE Transactions on Power Electronics, vol. 24, no. 6, pp. 1444-1452, Jun. 2009, doi: 10.1109/TPEL.2009.2016097.

[15] G. Shen, X. Zhu, J. Zhang, and D. Xu, "A new feedback method for PR current control of LCL-filter-based grid-connected inverter," IEEE Transactions on Industrial Electronics, vol. 57, no. 6, pp. 2033-2041, Jun. 2010, doi: 10.1109/TIE.2010.2040552.

[16] M. Gaiceanu, "Advanced state feedback control of grid-power inverter," Energy Procedia, vol. 14, pp. 1464-1470, 2012, doi: 10.1016/j.egypro.2011.12.1118.

[17] J. Dannehl, F. W. Fuchs, and P. B. Thøgersen, "PI state space current control of grid-connected PWM converters with LCL filters," IEEE Transactions on Power Electronics, vol. 25, no. 9, pp. 2320-2330, Sep. 2010, doi: 10.1109/TPEL.2010.2047408.

[18] W. Zhao, D. D. C. Lu, and V. G. Agelidis, "Novel current control of grid-connected boost-inverter with zero steady-state error," in Conference Proceedings - IEEE Applied Power Electronics Conference and Exposition - APEC, Mar. 2011, pp. 1267-1272, doi: 10.1109/APEC.2011.5744755

[19] M. Xue, Y. Zhang, Y. Kang, Y. Yi, S. Li, and F. Liu, "Full feedforward of grid voltage for discrete state feedback controlled gridconnected inverter with LCL filter," IEEE Transactions on Power Electronics, vol. 27, no. 10, pp. 4234-4247, Oct. 2012, doi: 10.1109/TPEL.2012.2190524.

[20] S. Harasis, Y. Sozer, M. Elbuluk, and H. Abu-Rub, "A novel DC link energy shaping process for minimizing the transient frequency variations in microgrids," in Conference Proceedings - IEEE Applied Power Electronics Conference and Exposition APEC, Mar. 2019, vol. 2019-March, pp. 3274-3280, doi: 10.1109/APEC.2019.8721991.

[21] F. Memon and C. Shao, "An optimal approach to online tuning method for PID type iterative learning control," International Journal of Control, Automation and Systems, vol. 18, no. 8, pp. 1926-1935, Feb. 2020, doi: 10.1007/s12555-018-0840-0.

[22] S. Albatran, I. A. Smadi, and H. A. Bataineh, "Generalized optimal and explicit PI/PID tuning formulas for underdamped secondorder systems," International Journal of Control, Automation and Systems, vol. 18, no. 4, pp. 1023-1032, Nov. 2020, doi: 10.1007/s12555-019-0178-2.

[23] E. A. Molina-Viloria, J. E. Candelo-Becerra, and F. E. Hoyos Velasco, "Reactive power sharing among distributed generators in a microgrid by using virtual current," International Journal of Power Electronics and Drive Systems (IJPEDS), vol. 12, no. 1, pp. 99-111, Mar. 2021, doi: 10.11591/ijpeds.v12.i1.pp99-111.

[24] R. Perez-Ibacache, C. A. Silva, and A. Yazdani, "Linear state-feedback primary control for enhanced dynamic response of AC microgrids," IEEE Transactions on Smart Grid, vol. 10, no. 3, pp. 3149-3161, May 2019, doi: 10.1109/TSG.2018.2818624.

[25] D. J. Clements and P. M. Frank, "The robustness properties of the linear quadratic regulators for singular systems," IEEE Transactions on Automatic Control, vol. 38, no. 1, pp. 96-100, 1993, doi: 10.1109/9.186315.

[26] E. Radwan, M. Nour, A. Baniyounes, K. S. Al-Olimat, and E. Awada, "Direct control of active and reactive power for a gridconnected single-phase photovoltaic inverter," International Journal of Power Electronics and Drive Systems (IJPEDS), vol. 12, no. 1, pp. 139-150, Mar. 2021, doi: 10.11591/ijpeds.v12.i1.pp139-150. 